\title{
Distribution Profile of Candida Species Involved in Angular Cheilitis Lesions Before and After Denture Replacement
}

\author{
Abbas Ali jafari ${ }^{1}$, Mohammad Hossein Lotfi-Kamran ${ }^{2, *}$, Abbas Falah-Tafti ${ }^{2}$, Saeeb Shirzadi ${ }^{2}$ \\ ${ }_{1}^{1}$ Medical School, Shahid Sadoughi University of Medical sciences, Yazd, IR Iran \\ 2 Dentistry School, Shahid Sadoughi University of Medical Sciences, Yazd, IR Iran \\ *Corresponding author: Mohammad Hossein Lotfi-Kamran, Dentistry School, Daha-Fajr Boulevard, Shahid Sadoughi University of Medical Sciences, Yazd, IR Iran. Tel: +98-3518228717, \\ Fax:+98-3518367668, E-mail: jaabno@gmail.com.
}

Received: February 20, 2013; Revised: Jun 05, 2013; Accepted: Jun 17, 2013

\begin{abstract}
Background: Angular cheilitis known as anoral candidiasis manifestation is deep fissures with ulcerated appearance, which affects angles of the mouth. Decreasing the vertical dimension(VD) of face in the elderly denture users is one of the predisposing factors for heavy colonization of Candida spp. in the cheek angles resulting angular cheilitis. Correcting vertical dimension by a new denture replacement can decrease Candida spp. colonization to prevent or improve the angular cheilitis lesions.

Objectives: The current study aimed to determine the distribution profile of Candida species isolated from cheek angles of patients with old denture before and after replacing with new ones.

Materials and Methods: Twenty eight complete denture users with decreased ridge, and outwear complete dentures, who referred for denture replacement, were randomly selected and their lip angles were cultured before and 3 months after using new dentures. Frequency and the species of isolated Candida spp. colonies before denture replacement and 3 months after using new dentures and correction of their vertical dimension were compared using Mann-Whitney statistical tests by SPSS software.

Results: All samples were colonized before denture replacement, though 3 months after using new dentures, only few cultures were positive. A significant statistical difference was observed between Candida colonization before and 3 months after denture replacement $(\mathrm{P}$ $=0.0001$ ). Candida albicans, C. tropicalis, C. krusei, C. parapssilosis and C. glabrata were isolated from lesions.

Conclusions: The results of the current study suggest that long term use of dentures can cause a wide range of Candida species colonization, resulting angular cheilitis. There was a need for an oral manifestation management-based strategy focusing on clinical and preventative treatment. Angular cheilitis can be prevented by changing and replacing a new denture to modify the face vertical dimension, and improve the angular cheilitis lesions.
\end{abstract}

Keywords: Candida Colonization; Angular Cheilitis; Denture; C. albicans

\section{Background}

Candida species, which are a part of the human oral microbial flora, in particular Candida albicans, are the main etiologic agents responsible for the development of oral candidiasis. These funguses are known as the commensally intra-oral microorganism, which varies from $20 \%$ to $50 \%$ in a healthy edentulous population and up to $75 \%$ in denture-wearers (1). The manifestation of oral candidiasis can occur in many different forms including median rhomboid glossitis, atrophic glossitis, denture stomatitis, and angular cheilitis (2-4). Risk factors for the development of oral candidiasis include immunosuppression, wearing dentures, pharmacotherapeutics, smoking, infancy and old age, endocrine dysfunction, and decreased salivation. The rapid development and spread of antifungal resistance, especially for treatment of candidiasis caused by non-albicans Candida species, have become an increasingly serious public health problem in a wide range of infectious diseases (5).

Angular cheilitis, one of the mucocutaneous lesions with deep fissures, affecting the angles of the elderly`s mouths with an ulcerated appearance, is associated with a variety of nutritional, systemic, and drug-related factors that may act exclusively or in combination with local factors. This endogenous infection is relatively common in edentulous or very old denture users in the elderly and immunocompromised, such as HIV-infected patients, diabetes mellitus, internal malignancy, and anemia (6). However angular cheilitis is infectious in origin and the patients may complain of burning of their lip angels, and several predisposing factors such as dentures, which altered vertical dimension of occlusion and lip support, avitaminosis, particularly deficiencies of Riboflavin and anemia may interact (7).

Different reports showed an increase in the frequency of angular cheilitis with increase in length of denture us- 
age, suggesting that the loss of vertical height could be an important cause, as it is assumed that the over-closure of the jaws will produce occlusive folds at the angles of the mouth in which saliva tends to collect and the skin subsequently becomes macerated, fissured and secondarily infected and colonized mainly with Candida and few bacterial species such as Staphylococcus aurous $(6,8)$. Poor oral hygiene, severe desorbed ridge and decrease in the face vertical height of occlusion can cause active colonization of Candida, which results in angular cheilitis among the elderly and institutionalized people leading to nutritional deficiency and impaired quality of life. (9-11). Management of the elderly mucosal Candidasis especially angular cheilitis is a major dentists' concern, especially in case of non-albicans species, which are less susceptible to common antifungal therapy than C. albicans.

\section{Objectives}

The main purpose of the present study was to compare the distribution profile of Candida species isolated from cheek angles before and 3 months after replacing of new denture inthe elderly with angular cheilitis.

\section{Materials and Methods}

Totally, twenty eight patients including 18 men and 10 women, with the mean age $73.5 \pm 7.8$ years, using complete denture admitted to dental clinic of Shahid Sadoughi University of Medical sciences (Yazd, Iran) took part in this study. All cases suffered from angular cheilitis confirmed by dentist. The patients with the history of diabetes mellitus, internal malignancy, immunosupression, and anemia, were all excluded from this study. A questioner including demographic and oral-dental questions was completed for each subject in the beginning. Their age, gender, history of the denture using, denture cleaning method, and prior treatment or medications for the symptom were interviewed.

For mycological examination, separate samples from their left and right side of lip lesions were collected using sterile swabs and direct smear were prepared. Specimens were also cultured on Sabouraud agar (Merck, Germany) plates, incubated at $35^{\circ} \mathrm{C}$ for 3 days. The density of isolated yeasts colonies were counted and determined as colony forming units (CFU/for each sample), signifying the number of Candida cells in each sample (12). The isolated Candida species were also identified by sub-culturing on CHROMagar medium (CHROMagar, France) and performing the germ tube production test, hyphae/pseudohyphae and chlamidospores growth, carbohydrate fermentation and assimilation methods as described by
Sandven (12). Three months after the denture replacement and using new complete dental prostheses, their lip angles' swab samples were again cultured for another mycological examination as described before (Figure 1). The density (mean of isolated colony forming units per each sample) and the species of isolated Candida colonies before and three months after using new dentures were compared with the Mann-Whitney test using SPSS15 software. Differences were considered statistically significant when $\mathrm{P}<0.05$.

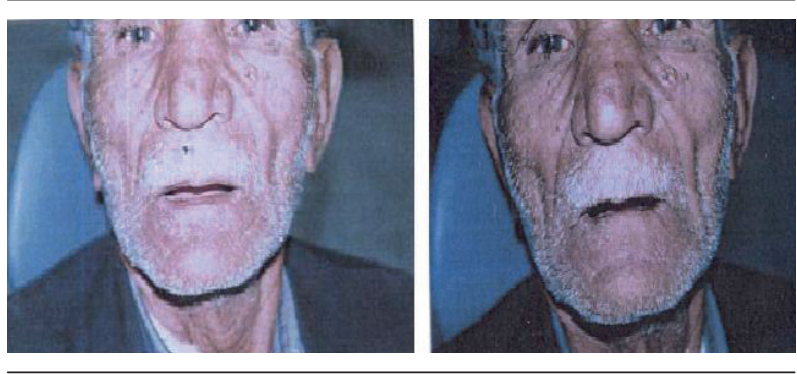

Figure 1. Appearance of Patients Before (Right), and After (Left) Denture Replacement

\section{Results}

All subjects had complete denture with mean $10.2 \pm 9.8$ years (ranging from 8.5 to 21.2 years) (Figure 2). Heavy colonization (more than 30 colonies) of Candida species was observed in most patients in the first mycological examination, whereas their Candidal load was significantly declined $(\mathrm{P}=0.0001)$ following 3 months after using new denture (Table1). Elderly men showed more angular cheilitis lesions than women in the present study $(\mathrm{P}=0.001)$. Only three cases showed slight colonization (less than 5 colonies) 3 months after denture replacement as a result of trauma and denture stomatitis. C. albicans was the major Candida species, isolated from $57.2 \%$ of cases, followed by C. tropicalis (17.9\%), C. krusei (10.7\%), C. parapsilosis and C. glabrata (7.1\% each) (Table 2).

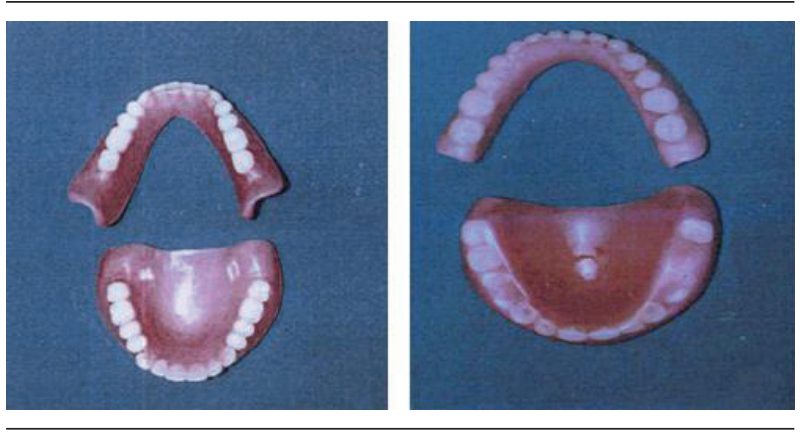


Figure 2. Old (Right) and new (Left) Complete Denture in the Present Study

Table 1. Frequency of Candida Colonization (CFU/sample) From Right and Left Angles of lip Before and 3 Months After Denture Replacement. $\mathrm{P}=0 / 0001$, Mann-Whitney test

\begin{tabular}{|c|c|c|c|c|}
\hline & \multicolumn{2}{|c|}{ Before } & \multicolumn{2}{|c|}{ After } \\
\hline & Mean $\pm S^{a}$ & $(\operatorname{Min}-\operatorname{Max})$ & Mean \pm SD & $(\operatorname{Min}-\operatorname{Max})$ \\
\hline Right & $28.6 \pm 11.3$ & $8-36$ & $3 \pm 1.2$ & $0-9$ \\
\hline Left & $17.2 \pm 6.8$ & $3-24$ & 0 & 0 \\
\hline
\end{tabular}

a Abbreviation: SD, Standard deviation

Table 2. Distribution Profile of Candida Species in Angular Chelitis Lesions Before and 3 Months After Using new Denture. $P=0.0001$

\begin{tabular}{lllll}
\hline & \multicolumn{2}{c}{ Before Denture Replacement } & \multicolumn{2}{c}{ After Denture Replacement } \\
\hline Candida species & Positive No. $(\%)$ & Mean \pm SD & Positive No. $(\%)$ & Mean \pm SD \\
\hline C. albicans & $16(57.2)$ & $40.3 \pm 16.2$ & $2(8.3)$ & $12 \pm 3.2$ \\
C. tropicalis & $5(17.9)$ & $32 \pm 12.5$ & 0 & 0 \\
C. krusei & $3(10.7)$ & $26 \pm 15$ & $1(4.2)$ & 7 \\
C. parapsilosis & $2(7.1)$ & $18 \pm 9.8$ & 0 & 0 \\
C. glabrata & $2(7.1)$ & $25 \pm 13.09$ & 0 & 0 \\
Total & $28(100)$ & & $3(12.5)$ &
\end{tabular}

\section{Discussion}

Candida species are known as the most prevalent opportunistic fungi, producing a high prevalence disease, candidiasis in human body, with the extremely varied localization. Colonization of Candida spp.in human mouth can promote oral candidiasis, with different manifestations. Angular cheilitis, one of the mucosal manifestations of oral candidiasis, results from colonization of Candida spp. in commissural folds, and satellite lesions on lips; however impaired immunity, diabetes mellitus and AIDS can alsoprovoke this lesion $(13,14)$. The present study was conducted in order to show the role of vertical dimension of occlusion modification in reduction of Candida species colonization in angular cheilitis lesions and improvement of this infection.

Angular cheilitis is usually seen in elderly and complete denture users, following the reduction in facial height caused by old age, bad-fitting dentures and over use of dentures $(6,7)$. Results of the present study showed that replacing the old dentures with the new ones usually reduces the angular cheilitis in denture wearers as reported by Mac Entee et al. (15). Pires et al.(16) reported denture stomatitis in $50 \%$ of subjects which decreased to $18.2 \%$ six months after using new denture. The present study revealed that $57.2 \%$ of cases were infected by C. albicans as the most prevalent species, which is supported by many similar studies (17-19). However, C. albicans, known as the most common isolated species in the present study, and heavy colonization of non-albicans Candida species were also seen in the lip lesion before denture replacement. Unfortunately, these species are less susceptible to common antifungal drugs than C. albicans. This may highlight a more precaution concerning the possible increased risk of systemic Candidias is in immunosuppressed elderly people and show the important role of VD correction in diminution of colonization and improving the angular cheilitis lesions (20).

In the current study angular cheilitis was seen more in men in comparison with women which was the same as that of the study, reported from Venezuela (17). A high prevalent colonization of Candida species is often documented in the elderly denture wearers. Candida species which adhere to acrylic surfaces of dentures play an important role in both the colonization and the pathogenesis of candidiasis $(18,19)$. For this reason, oral candidosis in the form of Candida-associated denture stomatitis and angular cheilitis are known as the most common diseases in the elderly denture wearers $(5,19,21)$. However in the present study only Candida species were isolated from lip lesions, but Ohman et al. (22) also isolated C. albicans and S. aurous. A positive Candida culture in the absence of other diagnostic signs and symptoms does not necessarily mean the mucosal disease of angular cheilitis (23), because this fungus is normally encountered as part of normal flora in human oral cavity and can be usually isolated without pathologic changes. Isolation of Candida species in culture should be supported by determination of characteristic budding yeast, pseudohyphae, and hyphae in the direct smear of the lesions (13). 
The results of the present study led to the conclusion that there was a need for an oral manifestation management-based strategy focusing on clinical and preventative treatment. Angular cheilitis, as oral manifestations are frequent in the edentulous elderly using old dentures, is caused by a wide range of Candida species colonization. This lesion can be controlled with changing and replacing a new denture to modify the face vertical dimension, and improve the angular cheilitis lesions.

\section{Acknowledgements}

This study was supported by the research affairs of Yazd Medical University as a dentistry student thesis. Also authors wish to thank Dr. Ezaddini for her support and Ms Nabi-poor and Ghafoorzadah for their laboratory works.

\section{Authors' Contribution}

Study concept and design: Mohammad Hosein Lotfi-Kamran. Analysis and interpretation of data: Abbas FalahTafti and Saeeb Shirzadi. Draft of the manuscript and critical revision of the manuscript for important intellectual content: Abbas Ali Jafari. Statistical analysis: Mohammad Hosein Lotfi-Kamran and Saeeb Shirzadi.

\section{Financial Disclosure}

Dr. Saeeb Shirzadi was financially supported for the material used in current study. Other authors of the present study confirmed that they haven't financial interests related to the material in the manuscript.

\section{Funding/Support}

This study was financially supported by the Vice-Chancellor for Research in Shahid Sadoughi University of Medical Sciences.

\section{References}

1. Radford DR, Challacombe SJ, Walter JD. Denture plaque and adherence of Candida albicans to denture-base materials in vivo and in vitro. Crit Rev Oral Biol Med.1999;10(1):99-116.

2. Samaranayake Lakshman P, K Cheung Lim, Samaranayake Yuthika H. Candidiasis and other fungal diseases of the mouth. Dermatol Therapy. 2002;15(3):251-269.

3. Gonsalves WC, Wrightson AS, Henry RG. Common oral conditions in older persons. Am Fam Physician. 2008;78(7):845-52.
4. Coelho CM, Sousa YT, Dare AM. Denture-related oral mucosal lesions in a Brazilian school of dentistry. J Oral Rehabil. 2004;31(2):135-9.

5. Neely MN, Ghannoum MA. The exciting future of antifungal therapy. Eur J Clin Microbiol Infect Dis. 2000;19(12):897-914.

6. Park KK, Brodell RT, Helms SE. Angular cheilitis, part 1: local etiologies. Cutis. 2011;87(6):289-95.

7. Sharon V, Fazel N. Oral candidiasis and angular cheilitis. Dermatol Ther. 2010;23(3):230-42.

8. Verma R, Balhara YP, Deshpande SN. Angular cheilitis after paroxetine treatment. J Clin Psychopharmacol. 2012;32(1):150-1.

9. Vigild M. Oral mucosal lesions among institutionalized elderly in Denmark. Community Dent Oral Epidemiol. 1987;15(6):309-13.

10. Frenkel HF. Behind the screens: care staff observations on delivery of oral health care in nursing homes. Gerodontology. 1999;16(2):75-80.

11. Honda E. Oral microbial flora and oral malodour of the institutionalised elderly in Japan. Gerodontology. 2001;18(2):65-72.

12. Terai H, Shimahara M. Atrophic tongue associated with Candida. J Oral Pathol Med. 2005;34(7):397-400.

13. Terai H, Shimahara M. Atrophic tongue associated with Candida. J Oral Pathol Med. 2005;34(7):397-400.

14. Rogers RS, Lotti TM, Parih LC, Rogers RS. Disease of the lips. In: Rogers RS, Lotti TM, Parih LC, Rogers RS, editors.Oral disease, Textbook and atlas.New York: Springer-Verlag;1999. p. 227-231.

15. Difonzo EM, Campanile GL, Lotti TM, Parih LC, Rogers RS. Candidosis: candidiasis, moniliasis, thrush. In: Difonzo EM, Campanile GL, Lotti TM, Parih LC, Rogers RS, editors.Oral disease, Textbook and atlas.New York: Springer-Verlag; 1999. p. 114-118.

16. MacEntee MI, Glick N, Stolar E. Age, gender, dentures and oral mucosal disorders. Oral Dis. 1998;4(1):32-6.

17. Pires FR, Santos EB, Bonan PR, De Almeida OP, Lopes MA. Denture stomatitis and salivary Candida in Brazilian edentulous patients. J Oral Rehabil. 2002;29(11):1115-9.

18. Mujica V, Rivera H, Carrero M. Prevalence of oral soft tissue lesions in an elderly venezuelan population. Med Oral Patol Oral Cir Bucal. 2008;13(5):E270-4.

19. Scully C, van Bruggen W, Diz Dios P, Casal B, Porter S, Davison MF Down syndrome: lip lesions (angular stomatitis and fissures) and Candida albicans. Br J Dermatol. 2002;147(1):37-40.

20. Panagoda GJ, Ellepola AN, Samaranayake LP. Adhesion to denture acrylic surfaces and relative cell-surface hydrophobicity of Candida parapsilosis and Candida albicans. APMIS. 1998;106(7):73642.

21. Krcmery V, Barnes AJ. Non-albicans Candida spp. causing fungaemia: pathogenicity and antifungal resistance. J Hosp Infect. 2002;50(4):243-60.

22. Webb BC, Thomas CJ, Willcox MD, Harty DW, Knox KW. Candidaassociated denture stomatitis. Aetiology and management: a review. Part 1. Factors influencing distribution of Candida species in the oral cavity. Aust Dent J.1998;43(1):45-50.

23. Ohman SC, Dahlen G, Moller A, Ohman A. Angular cheilitis: a clinical and microbial study. J Oral Pathol.1986;15(4):213-7.

24. Fotos PG, Vincent SD, Hellstein JW. Oral candidosis. Clinical, historical, and therapeutic features of 100 cases. Oral Surg Oral Med Oral Pathol.1992;74(1):41-9. 